Check for updates

Cite this: RSC Adv., 2019, 9, 23718

\title{
EMI shielding of ABS composites filled with different temperature-treated equal-quantity charcoals
}

\begin{abstract}
Krishna Kamal Halder, ${ }^{\text {ab }}$ V. K. Sachdev, (D) *a Monika Tomar (D c and Vinay Gupta (D) ${ }^{\text {a }}$
Acrylonitrile-butadiene-styrene (ABS) composites were prepared by dry mixing equal-quantity (20 wt\%) charcoals treated at different temperatures followed by hot compression. Processing parameters were kept the same. Seven samples of the same charcoal were modified for carbonization at different temperatures varying from $500{ }^{\circ} \mathrm{C}$ to $1100{ }^{\circ} \mathrm{C}$ in steps of $100{ }^{\circ} \mathrm{C}$. Temperature treatment of charcoal crafts an increase in the conductivity of ABS composites, primarily accountable for the enhancement of shielding. The electromagnetic shielding effectiveness in the X-band (8.2-12.4 GHz) has been discovered to significantly increase for composites with ascending temperature-treated charcoals. An abrupt increase in the conductivity of ABS composites containing equal quantities of charcoal subjected to enhanced temperature treatments truly explains the effective absorption behaviour. The composite containing $1100{ }^{\circ} \mathrm{C}$ temperature-treated charcoal shows absorption-dominated SE of $\sim 36.8 \mathrm{~dB}$ at 11.6 $\mathrm{GHz}$. Dielectric behaviour proclaims a decrease in dielectric loss $\left(\varepsilon^{\prime \prime}\right)$ with an increase in the frequency. Besides this, the increased carbonization temperatures also show increased porosity and high dielectric losses. The scanning electron microscopy studies validate the increase in the porosity of charcoals due to the increase in the treatment temperature. The results are promising for the development of custommade shielding composites possessing equal quantities of charcoal treated at enhanced temperatures.
\end{abstract}

Received 25th April 2019
Accepted 26th June 2019

DOI: $10.1039 / c 9 r a 03080 h$

rsc.li/rsc-advances polydimethylsiloxane composites have been reported to be applied in radio absorbers. ${ }^{6}$ Indeed, polymer composites have a wide range of applications. In automobile industries, the focus is on the replacement of metal alloys with high-strength polymer composites. ${ }^{7}$ The polymer composites are electrical insulators in general. To make them conducting, different types of conducting fillers such as MWCNTs, graphene, graphite, metal powder and carbon fibre have been used. ${ }^{5,8-13}$ CPCs' low cost, easy processing, as well as suitable matrices for biomolecule immobilization qualified them for the development of polyaniline-based biosensors. ${ }^{14}$ Additionally, CPCs are used for applications in field emission transistors, supercapacitors, batteries, solar cells and biomedical instruments. ${ }^{7,15,16}$ Although MWCNTs are the most explored materials as fillers because of their high aspect ratio and good conductivity, the high aspect ratio develops strong van der Waals intermolecular interactions that causes much difficulty in the uniform dispersion of MWCNTs in the polymer matrix. ${ }^{17}$ The electrical properties of various forms of carbon-based polymer composites have attracted considerable attention in many scientific applications including EMI shielding. The potential of 2D materials for microwave absorption and EMI shielding applications in the $\mathrm{GHz}$ frequency range ${ }^{18}$ has been reported. Reduced graphene oxide (RGO) as a filler is a good contender for EMI shielding applications at a higher temperature range. ${ }^{19}$ In one report, carbon fibre-incorporated silica composites for EMI shielding
${ }^{a}$ Department of Physics and Astrophysics, University of Delhi, Delhi-110007, India. E-mail:vk_sachdev@yahoo.com

${ }^{b}$ Kirori Mal College, University of Delhi, Delhi-110007, India

${ }^{c}$ Miranda House, University of Delhi, Delhi-110007, India 
and microwave absorption applications $\mathrm{s}^{\mathbf{2 0}}$ are described. The conductive nature of carbon results in an enhanced EMI shielding property in carbon-filled polymer composites. These composites are broadly divided into two categories, namely, the $\mathrm{sp}^{2}$-bonded atoms having hexagonal stacking and $\mathrm{sp}^{3}$-bonded atoms of carbon having tetrahedral geometry. It is reported that carbonization, i.e. temperature treatment, changes the chemical and electrical properties of carbon-based materials. ${ }^{21}$ During the process of carbonization/temperature treatment of wood, $\mathrm{sp}^{2}$-bonded atoms are formed. ${ }^{22}$ The electrical resistivity of carbonized materials is stated to be strongly dependent on the carbonization temperature. Reports describe that carbonized wood behaves as an insulator for carbonization temperatures below $500{ }^{\circ} \mathrm{C}$, while above $800{ }^{\circ} \mathrm{C}$, its resistivity decreases considerably, ${ }^{23}$ exhibiting a good conductivity with the increase in the carbonization temperature up to $1800{ }^{\circ} \mathrm{C} .{ }^{24}$ This feature boosts the suitability of carbon-based compounds (charcoal) as fillers in polymer composites, particularly for EMI shielding applications. Charcoal/UHMPE polymer composites have been described to show enriched mechanical properties on carbonization, ${ }^{25}$ but there is no report on the study of EMI shielding properties pertinent to the carbonization temperature of charcoal.

In the present work, acrylonitrile-butadiene-styrene (ABS) polymer composites containing equal quantities of conductive charcoal carbonized at different temperatures are developed and investigated for EMI shielding applications. ABS is used as a polymer matrix. It is a thermoplastic resin copolymer of acrylonitrile, butadiene and styrene. It exhibits hard and rigid nature, good heat resistance, excellent performance at high and low temperatures, electroplatability, light-weight structure and good dimensional stability. ${ }^{26}$ It offers good impact strength and chemical resistance. It also possesses good adhesive properties and printability. ${ }^{27}$ In this research, conductive ABS polymer composites using equal amounts of charcoal carbonized at different temperatures were developed. The carbonization temperature of $\sim 800{ }^{\circ} \mathrm{C}$ improves the Young's modulus of charcoal, ${ }^{28}$ which enhances the mechanical strength of the composites. ${ }^{25,29}$ The process of additional carbonization of charcoal through temperature treatments is a noteworthy approach to modify the electrical conductivity and morphology of the composite that makes the charcoal-customized conductive filler for EMI shielding applications.

\section{Experimental}

ABS-92 was procured from Lanxess India in granular form and pulverized to particle size $<400$ micron. Hard wood commercial charcoal was selected because of its ability for additional carbonization through temperature treatments. Further carbonization of charcoal was achieved in a $\mathrm{N}_{2}$ atmosphere using a Tubular furnace procured from Jupiter Engineering Works India. Desired temperatures in the range of $500-1100^{\circ} \mathrm{C}$ were regulated within the accuracy of $\pm 1 \%$ for 1 hour. Seven temperature-treated charcoal samples correspondingly at $500,600,700,800,900,1000$ and $1100{ }^{\circ} \mathrm{C}$ were obtained. Each charcoal sample was crushed to powder and its $20 \mathrm{wt} \%$ representative fixed quantity was mixed into the $\mathrm{ABS}$ powder by means of a magnetic stirrer for 200 minutes. Herein, $20 \mathrm{wt} \%$ quantity of the charcoal was chosen since the conductivity percolation threshold of the charcoal without temperature treatment in ABS composites is $\sim 10 \mathrm{wt} \%$ and the probability of some good firsthand information is more. The resulting mixture was heated at $115{ }^{\circ} \mathrm{C}$ for 15 minutes in a rectangular X-band wave guide-shaped pressure mould, brought back to a lower temperature of $90{ }^{\circ} \mathrm{C}$ and subsequently compressed at a constant pressure of $75 \mathrm{MPa}$ for 15 minutes. Three composite pellets were prepared for each temperature-treated charcoal. The electrical conductivity $(\sigma)$ values of composites were determined using a Keithley 4200 system-210 V/ $100 \mathrm{~mA}, 0.1 \mathrm{fA}$ resolution setup, while EMI Shielding effectiveness (SE) evaluations were performed using an Agilent vector network analyser (VNA), model N5230C PNA-L $10 \mathrm{MHz}$ to $40 \mathrm{GHz}$ in the Xband frequency range, the same as earlier. ${ }^{30} S$-parameters were measured in the same range. For morphological studies of composites, a ZEISS FESEM was used. The ASTM D792 method was employed for the assessment of density of each carbonized charcoal. For XRD, Rigaku Ultima-IV was used, and FTIR spectroscopy of charcoal was performed on a PerkinElmer (Frontier).

\section{Results and discussion}

\subsection{XRD studies}

Fig. 1 represents the XRD patterns for treated charcoals at carbonization temperatures of $500{ }^{\circ} \mathrm{C}, 800{ }^{\circ} \mathrm{C}$ and $1100{ }^{\circ} \mathrm{C}$. For each carbonization temperature, two diffraction peaks were obtained at angles $(2 \theta)$ of $23.38^{\circ}$ and $43.18^{\circ} .{ }^{31,32}$ The peak at $43.18^{\circ}$ becomes prominent with the increasing carbonization temperature. In this whole XRD pattern, no sharp peak is noticed, which implies that the carbonized charcoal is amorphous in nature.

\subsection{FTIR studies}

The FTIR spectra of the untreated charcoal and the $1100{ }^{\circ} \mathrm{C}$ temperature-treated carbonized charcoal are displayed in Fig. 2. The black colour of both untreated and treated charcoals

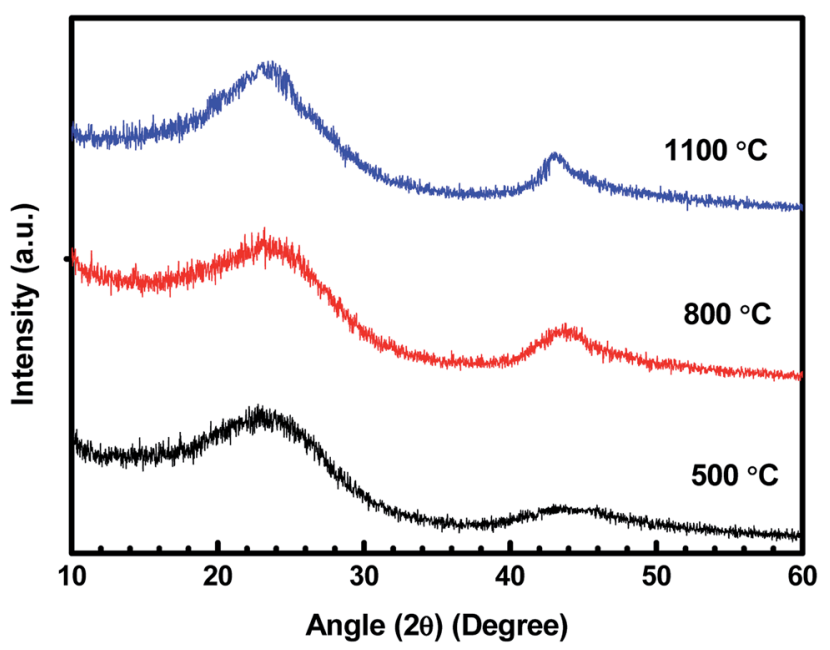

Fig. 1 XRD patterns of carbonized charcoals at $500{ }^{\circ} \mathrm{C}, 800^{\circ} \mathrm{C}$ and $1100{ }^{\circ} \mathrm{C}$ carbonization temperatures. 
indicates higher absorption of visible spectra. Consequently, the FTIR spectra have not been clearly resolved. The peak at $880 \mathrm{~cm}^{-1}$ in the spectrum of $1100{ }^{\circ} \mathrm{C}$ temperature-treated carbonized charcoal represents the aromatic outer mode of vibration, which is absent in the spectrum of untreated charcoal. ${ }^{23}$ The $\mathrm{C}=\mathrm{C}$ vibrational band represented by $1450 \mathrm{~cm}^{-1}$ and $1630 \mathrm{~cm}^{-1}$ appeared after the carbonization of charcoal. ${ }^{33}$ The peak at $1450 \mathrm{~cm}^{-1}$ could be attributed to the $\mathrm{C}-\mathrm{H}$ deformation in lignin and carbohydrate. ${ }^{34}$ The peak corresponding to the $-\mathrm{C}=\mathrm{O}$ functional group has been observed at $1750 \mathrm{~cm}^{-1} .^{35}$ The peak at $2340 \mathrm{~cm}^{-1}$ in the spectrum of untreated charcoal may be assigned to the dissolved $\mathrm{CO}_{2}$ present in the untreated charcoal, ${ }^{36}$ which disappears after carbonization at higher temperatures $\left(1100{ }^{\circ} \mathrm{C}\right)$. The peaks appearing between $2800-$ $3000 \mathrm{~cm}^{-1}$ have been assigned to $\mathrm{CH}_{3}, \mathrm{CH}_{2}$ and $\mathrm{CH}$ functional groups. ${ }^{35} \mathrm{~A}$ decrease in the intensity at higher carbonization temperatures is observed.

\subsection{Conductivity}

The variation in the $\log (\sigma)$ values as a function of charcoal carbonization temperature for seven ABS-charcoal composite samples each containing $20 \mathrm{wt} \%$ of charcoal carbonized at different temperatures between 500 and $1100{ }^{\circ} \mathrm{C}$ in steps of $100{ }^{\circ} \mathrm{C}$ is shown in Fig. 3. Herein, $\sigma$ is the mean value of three samples of each composite corresponding to their carbonization temperature shown on the log scale because of large variations in $\sigma$ from $3.56 \times 10^{-5} \mathrm{~S} \mathrm{~cm}^{-1}$ to $4.81 \mathrm{~S} \mathrm{~cm}^{-1}$ over the temperature range of $500-1100{ }^{\circ} \mathrm{C}$. The maximum departure of $\sigma$ from the mean values is $\pm 0.24 \mathrm{~S} \mathrm{~cm}^{-1}$ for the largest value of $\sigma$ (at $1100{ }^{\circ} \mathrm{C}$ ).

It may be seen that the $\sigma$ value of the composites increases sharply from semiconducting to conducting range, $3.56 \times$ $10^{-5} \mathrm{~S} \mathrm{~cm}^{-1}$ to $2.99 \times 10^{-1} \mathrm{~S} \mathrm{~cm}^{-1}$ related to charcoals treated at $500{ }^{\circ} \mathrm{C}$ and $600{ }^{\circ} \mathrm{C}$. Beyond that, $\sigma$ tends towards saturation with an increase in the carbonization temperature. An almost flat value of $4.81 \mathrm{~S} \mathrm{~cm}^{-1}$ is obtained for the composite having

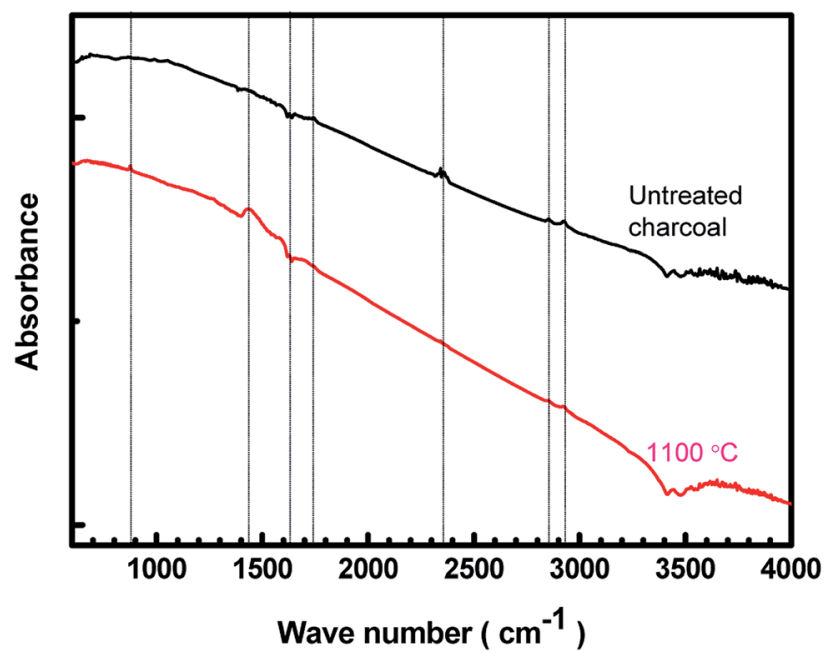

Fig. 2 FTIR spectra of untreated and $1100{ }^{\circ} \mathrm{C}$ temperature-treated charcoals.

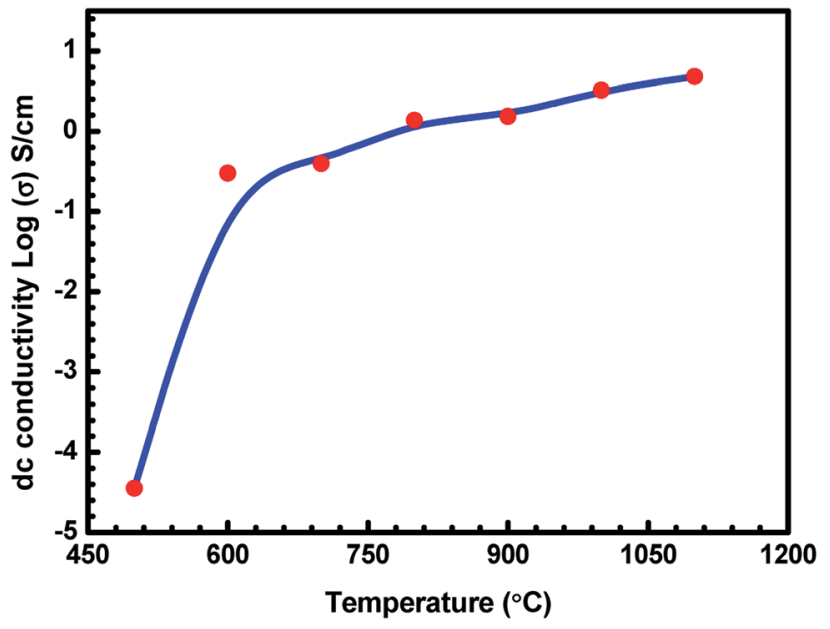

Fig. 3 Variation in dc conductivity $(\sigma)$ of ABS charcoal composites with the carbonization temperature.

charcoal carbonized at $1100{ }^{\circ} \mathrm{C}$ temperature. The increase in the carbonization temperature decreases the volatile stuffing within the charcoal, thereby increasing the content of carbon in the charcoal and forming a more graphitised carbon structure..$^{37,38}$ EDAX performed on $500{ }^{\circ} \mathrm{C}, 900{ }^{\circ} \mathrm{C}$ and $1100{ }^{\circ} \mathrm{C}$ temperaturetreated charcoals confirm the increase in the carbon content from $89.31 \mathrm{wt} \%$ with 95.64 at\% in charcoal treated at $500{ }^{\circ} \mathrm{C}$ to 91.85 wt\% with 96.73 at $\%$ in charcoal treated at $1100{ }^{\circ} \mathrm{C}$ through 91.62 wt $\%$ with 96.62 at\% in charcoal treated at $900{ }^{\circ} \mathrm{C}$. The saturating carbon content with the increase in temperature authenticates the conductivity behaviour in this range of temperature. Hydrogen would be released due to the breakage of $\mathrm{C}-\mathrm{H}$ bonds. Initially up to $600{ }^{\circ} \mathrm{C}$, the removal of volatile materials is likely to be the largest, and beyond that, the removal of volatile substance decreases. The breakage of $\mathrm{C}-\mathrm{H}$ bonds produces free electrons, responsible for the increase in the conductivity of charcoal. Moreover, increasing the carbonization temperature increases the $\mathrm{C} / \mathrm{H}$ ratio, which leads to a rise in the degree of aromatization of charcoal. ${ }^{38}$ The aromatization of charcoal would lead to a decrease in the resistivity since the aromatic nuclei have low energy gap and high $\sigma$ values. ${ }^{38,39}$ Here, in these charcoal/ABS composites, mainly conduction and hopping are the two possible ways of charge transportation through a network of conducting pathways. The increasing electrical conductivity of the carbonized charcoal at elevated carbonization temperatures can be explained assuming the formation of more graphitised carbon structures $^{37,38}$ and the migration of electrons via conduction and hopping through the defects and interface between the disorder of the graphitised carbon structure. ${ }^{\mathbf{2 0 , 4 0 , 4 1}}$ The increase in the carbonization temperature produces an increase in the graphitised carbon concentration, which results in a decrease in the distance between graphitised carbon particles, responsible for the rising level of conductivity of carbonized charcoals. The temperature-treated charcoal with improved conductivity forms a conducting network within the polymer composites, which converts the insulating polymer into semiconducting or 
conducting polymer composites, resulting in a higher electrical conductivity. ${ }^{42}$ The porosity and surface area of temperaturetreated charcoals are anticipated to increase with temperature, improving the surface chemistry of charcoals.

\subsection{Density}

Seven temperature-treated charcoals obtained correspondingly at $500,600,700,800,900,1000$ and $1100{ }^{\circ} \mathrm{C}$ were put to density measurements. The density of each carbonized charcoal has been measured using the ASTM D792 method through the equation $\omega_{\mathrm{a}} /\left(\omega_{\mathrm{a}}-\omega_{1}\right)$, where $\omega_{\mathrm{a}}$ and $\omega_{1}$ represent the weight of the sample in air and distilled water, respectively. The digital balance used for weighing was accurate to $0.0001 \mathrm{~g}$. The density of the carbonized charcoals is noticed to decrease up to $800{ }^{\circ} \mathrm{C}$ remarkably. Above $800{ }^{\circ} \mathrm{C}$, the fall in the density of charcoals is in a very slow pace. The density of the untreated charcoal is $\sim 0.705 \mathrm{~g} \mathrm{~cm}^{-3}$, whereas the density of $800{ }^{\circ} \mathrm{C}$ temperaturetreated charcoal is $\sim 0.511 \mathrm{~g} \mathrm{~cm}^{-3}$. The density of $1100{ }^{\circ} \mathrm{C}$ temperature-treated carbonized charcoal is $0.474 \mathrm{~g} \mathrm{~cm}^{-3}$ because up to $800{ }^{\circ} \mathrm{C}$ most of the volatile substances in the charcoal got evaporated.

\subsection{Morphological studies}

Pristine ABS has a featureless morphology. Undoubtedly, the incorporation of charcoals into its matrix would change the morphology and microstructure of composites. However, it is important to see how the same charcoal in equal amounts but treated at different temperatures behaves in the ABS matrix. FESEM studies reveal the structural changes in ABS composites containing charcoals treated at increasing carbonization temperatures. Fig. 4(a-d) are the FESEM micrographs of cryofractured pellets of ABS composites prepared with charcoals treated at 500, 700, 900 and $1100{ }^{\circ} \mathrm{C}$ temperatures. The presence of discrete and small-sized conducting composite particles noticeable in Fig. 4(a) may be responsible for the low value of $\sigma$, whereas large cohesive conducting composite particles with pores shown in Fig. 4(b-d) endorse a high $\sigma$ value. The removal of volatile materials and the increase in the $\mathrm{C} / \mathrm{H}$ ratio at elevated carbonization temperatures of charcoals have probably made it possible to form chunks of conducting composites in ABS composites. The increase in the carbonization temperature increases the surface area and porosity of charcoals, ${ }^{43}$ leading to the formation of foam-like structures. During fabrication of composites, the charcoal powder get coated on to the ABS particles and on pressure compaction localized in to the interfacial positions. Pressure compaction enhances the closeness between the particles and thereby the $\sigma$ value.

\subsection{Dielectric studies}

The dielectric properties of a polymer composite mainly depend on the permittivity, conductivity, and relative volume fraction of constituents in the composite in addition to the morphology of the system. ${ }^{44}$ The dielectric constant depends on the porosity and grain size of the filler. With the increase in the pore and grain sizes, the dielectric constant decreases. ${ }^{45}$ As the carbonization temperature increases, the pore size of the charcoal increases and the density decreases. The dielectric constant is recognised as $\varepsilon=\varepsilon^{\prime}+j \varepsilon^{\prime \prime}$, where $\varepsilon^{\prime}$ and $\varepsilon^{\prime \prime}$ are the real and imaginary parts of the dielectric constant, respectively. ${ }^{46,47}$ Percolating composites containing conducting fillers display the noteworthy permittivity due to interfacial polarization, which appears at the interface of different materials. ${ }^{48,49}$ The mobile charges in different parts of composites are obstructed at the interface consisting of two materials of different permittivities and conductivities. These bunged up charges are incapable to discharge freely amass at an interface and give rise to an overall field distortion. This results in an increase in the capacitance of the system as a result of high interfacial polarization. ${ }^{44}$ The values for $\varepsilon^{\prime}$ and $\varepsilon^{\prime \prime}$ for charcoal/ABS pellets are evaluated using the Nicholson-Ross-Weir method from $S$ parameter measurements using a vector network analyser as described earlier. ${ }^{42}$

Using free electron theory, $\varepsilon^{\prime \prime}$ can be written as, ${ }^{20,50}$

$$
\varepsilon^{\prime \prime} \approx \frac{\sigma(T)}{2 \pi \varepsilon_{0} f}
$$

where $\sigma(T), \varepsilon_{0}$ and $f$ are the electrical conductivity, dielectric constant in vacuum and frequency, respectively. From eqn (1), it can be seen that electrical conductivity plays an important role in developing $\varepsilon^{\prime \prime}$. Fig. 5 shows the variation in dielectric loss $\left(\varepsilon^{\prime \prime}\right)$ of ABS-charcoal composites as a function of frequency possessing $20 \mathrm{wt} \%$ charcoal of different carbonization temperatures. It may be seen that $\varepsilon^{\prime \prime}$ increases with the increase in the carbonization temperature, which may be endorsed to the fact that an increase in the carbonization temperature of charcoals enhances its conductivity, so more free charges accumulate at the interface leading to an increase in loss. As a function of frequency, $\varepsilon^{\prime \prime}$ is seen to decrease for all the samples. It may also be observed that $\varepsilon^{\prime \prime}$ increases from 5 to 45 with the rise in the carbonization temperature from $500{ }^{\circ} \mathrm{C}$ to $1100{ }^{\circ} \mathrm{C}$, which may be endorsed to the fact that the increase in the carbonization temperature of charcoal enhances its conductivity, and hence more free charges accumulate at the interface leading to an increase in loss. However, the real part of dielectric $\varepsilon^{\prime}$ is found to be almost constant (Table 1). The average value is $\sim 15$ at $8.2 \mathrm{GHz}$ for composites with a carbonization temperature from $500{ }^{\circ} \mathrm{C}$ to $1100{ }^{\circ} \mathrm{C}$. The reason may be assigned to the fixed quantity of various temperature-treated charcoals in composites.

Fig. 6 represents the variation of loss $\tan \delta$ with the carbonization temperature of charcoals in ABS-carbonized charcoal composites, calculated using $\tan \delta=\varepsilon^{\prime \prime} / \varepsilon^{\prime}$. Dielectric loss $\tan \delta$ is the dissipation of energy. Different physical phenomena like electrical conduction, dielectric relaxation and loss from non-linear processes contribute to loss $\tan \delta .^{51}$ In Table 1 , the value of $\varepsilon^{\prime \prime}$ increases with the increasing carbonization temperature, which can be explained using eqn (1). It can be seen that the electrical conductivity plays an important role in developing $\varepsilon^{\prime \prime}$. The values of $\varepsilon^{\prime}$ remain almost constant for all the carbonization temperature as the quantity of different temperature treated charcoals in composites is equal. Therefore, $\tan \delta$ increases with the rising carbonization temperature since the rise in carbonization temperature raises the conductivity of the charcoal. This outcome reveals that the ABS 

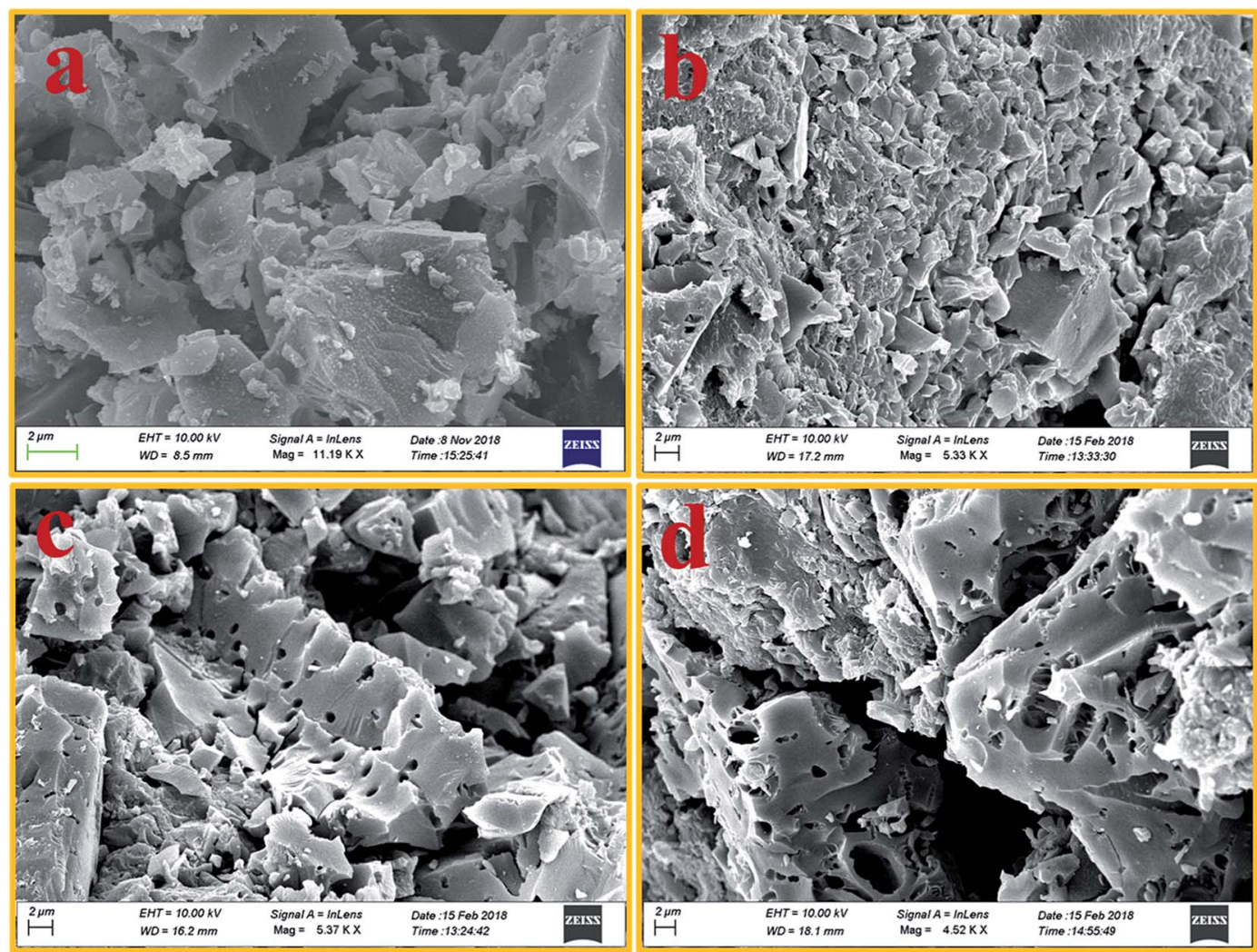

Fig. 4 (a-d) FESEM images of $500^{\circ} \mathrm{C}, 700^{\circ} \mathrm{C}, 900^{\circ} \mathrm{C}$ and $1100^{\circ} \mathrm{C}$ temperature-treated charcoals/ABS composites, respectively.

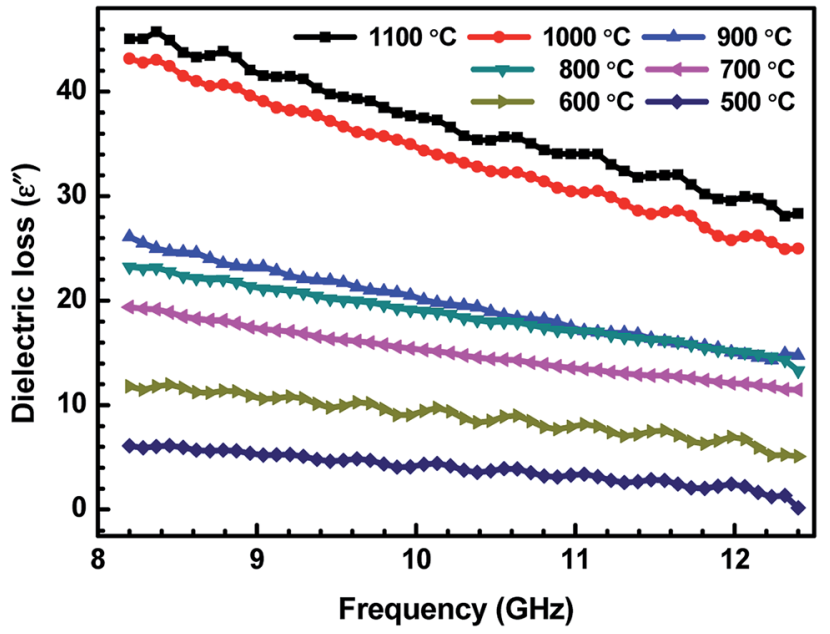

Fig. 5 Variation of dielectric loss $\left(\varepsilon^{\prime \prime}\right)$ of ABS charcoal composites with the frequency for different carbonization temperatures.

composites become more lossy with the growing conductivity of charcoal particles.

\subsection{Shielding measurements}

Shielding is the attenuation of electromagnetic (EM) signals after a blockade is introduced between the radiation source and the object to be protected. Fig. 7 illustrates the schematic of shielding mechanisms.
There are three mechanisms of EMI shielding: reflection, absorption and Multiple Internal Reflection (MIR). Reflection is a surface phenomenon as it occurs at the interface of two materials, whereas absorption is a volume phenomenon and its contribution increases with the increase in the shield thickness. Multiple reflection is significant only in the case of thin shields and can be neglected for thick shields when loss due to absorption $\mathrm{SE}_{\mathrm{Abs}}$ becomes $>10 \mathrm{~dB},{ }^{52}$

$$
\mathrm{SE}_{\mathrm{Total}}=\mathrm{SE}_{\mathrm{Abs}}+\mathrm{SE}_{\mathrm{Ref}}+\mathrm{SE}_{\mathrm{MIR}}
$$

The SE values are determined using reflectance $(R)$, transmittance $(T)$ and absorbance $(A)$, which refer to the fraction of power incident $\left(P_{\mathrm{I}}\right)$, reflected $\left(P_{\mathrm{R}}\right)$, transmitted $\left(P_{\mathrm{T}}\right)$ and absorbed $\left(P_{\mathrm{A}}\right)$ respectively by the shield, defined as:

$$
R=\frac{P_{\mathrm{R}}}{P_{\mathrm{I}}}, \quad T=\frac{P_{\mathrm{T}}}{P_{\mathrm{I}}} \text { and } A=1-(R+T)
$$

In terms of $S$-parameters

$S_{11}(\mathrm{~dB})=10 \times \log _{10}\left(\frac{P_{\mathrm{R}}}{P_{\mathrm{I}}}\right)=10 \times \log _{10}(R)=\mathrm{RL}($ Return Loss $)$

$$
S_{12}(\mathrm{~dB})=10 \times \log _{10}\left(\frac{P_{\mathrm{T}}}{P_{\mathrm{I}}}\right)=10 \times \log _{10}(T)=\mathrm{SE}\left(\mathrm{SE}_{\mathrm{Total}}\right)
$$


Table 1 Represents the data of $\varepsilon^{\prime}, \varepsilon^{\prime \prime}, A, R, T, \mathrm{SE}_{\mathrm{Ref}}, \mathrm{SE}_{\mathrm{Abs}}$ and $\mathrm{S} \mathrm{E}_{\mathrm{Total}}$

\begin{tabular}{|c|c|c|c|c|c|c|c|c|}
\hline $\begin{array}{l}\text { Carbonization } \\
\text { temperature }\left({ }^{\circ} \mathrm{C}\right)\end{array}$ & $\varepsilon^{\prime}$ & $\varepsilon^{\prime \prime}$ & $A$ & $R$ & $T$ & $\mathrm{SE}_{\text {Ref }}$ & $\mathrm{SE}_{\mathrm{Abs}}$ & $\mathrm{SE}_{\text {Total }}$ \\
\hline 500 & 13.13 & 6.11 & 49.82 & 39.63 & 10.55 & 2.19 & 7.58 & 9.77 \\
\hline 600 & 14.77 & 11.80 & 49.57 & 41.21 & 9.22 & 2.31 & 9.11 & 11.42 \\
\hline 700 & 13.80 & 19.38 & 47.25 & 51.19 & 1.56 & 3.11 & 14.96 & 18.07 \\
\hline 800 & 13.69 & 23.24 & 46.76 & 52.21 & 1.02 & 3.30 & 16.70 & 20.00 \\
\hline 900 & 18.25 & 26.10 & 35.10 & 64.55 & 0.33 & 4.51 & 20.23 & 24.74 \\
\hline 1000 & 15.99 & 43.16 & 36.03 & 63.80 & 0.16 & 4.41 & 23.46 & 27.87 \\
\hline 1100 & 14.75 & 45.06 & 35.27 & 64.69 & 0.02 & 4.26 & 31.85 & 36.11 \\
\hline
\end{tabular}

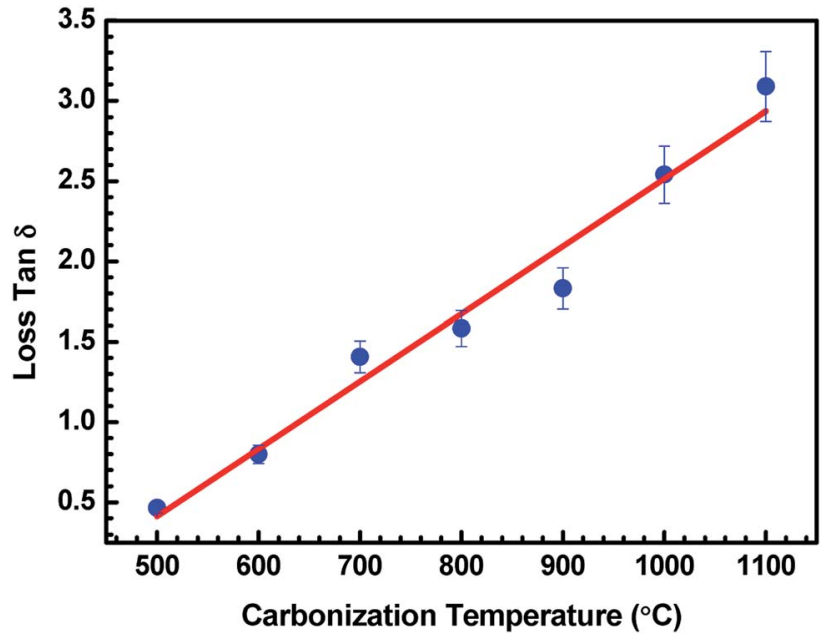

Fig. 6 Variation in $\tan \delta$ of ABS charcoal composites at a frequency of 8.2 GHz for different carbonization temperatures.

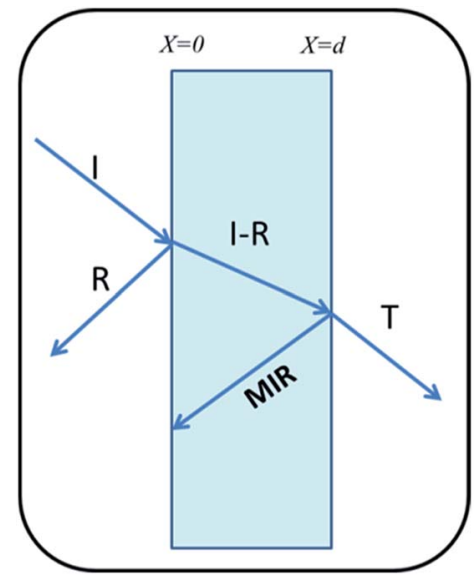

Fig. 7 Schematic of shielding mechanism.

$\mathrm{SE}_{\mathrm{Ref}}$ and $\mathrm{SE}_{\mathrm{Abs}}$ are evaluated using the following relations:

$$
\begin{gathered}
\mathrm{SE}_{\mathrm{Ref}}(\mathrm{dB})=10 \times \log _{10}(1-R) \\
\mathrm{SE}_{\mathrm{Abs}}(\mathrm{dB})=10 \times \log _{10}\left(\frac{P_{\mathrm{Abs}}}{P_{\mathrm{Pen}}}\right)=10 \times \log _{10}\left(\frac{T}{1-R}\right)
\end{gathered}
$$

$P_{\text {Abs }}$ and $P_{\text {Pen }}$ are the absorbed and penetrated power, respectively.

In the present work, the $\mathrm{SE}$ values are determined by measuring scattering parameters $S_{11} / S_{22}$ and $S_{12} / S_{21}$, obtained using two ports of vector network analyser. ${ }^{30} S$-parameters are stately with a regular fixed interval of $84 \mathrm{MHz}$ in the frequency range of 8.2-12.4 GHz. The uncertainties in SE measurements are between 0.07 and $1 \mathrm{~dB}$, using a VNA uncertainty calculator. ${ }^{42}$ Fig. 8(a and b) show the variation of total SE and evaluated value of SE absorption as a function of frequency for various ABScharcoal composites having charcoals carbonized at different temperatures.

Total SE and SE absorption, both are seen to be increasing with the increase in the treatment temperature of charcoals in the composites. Further, it may be seen that as a function of frequency, total SE and absorption SE both remain almost constant in the entire frequency range for all the samples. The evaluated value SE reflection is observed to be almost the same since the quantity of charcoals is the same in all the ABS composites. For ABS-charcoal composites having charcoal treated at $500{ }^{\circ} \mathrm{C}$, total $\mathrm{SE}$ is $\sim 9.9 \mathrm{~dB}$ at $11.6 \mathrm{GHz}$ frequency, which increases to $\sim 36.8 \mathrm{~dB}$ in the composite charcoal treated at $1100{ }^{\circ} \mathrm{C}$. Broadly, the increase in total $\mathrm{SE}$ is due to the increase in the conductivity of composites. Basically, ABS is an insulator and the charcoal is accountable for the increase in the electrical conductivity of the ABS-charcoal. As the carbonization temperature increases, the conductivity of charcoal increases due to the aromatization of charcoal, breakage of $\mathrm{C}-\mathrm{H}$ bonds and reduction of volatile substances. ${ }^{38}$ During the fabrication of composites, the charcoal powder is coated on the ABS particles and the probability of its migration to interfacial positions may not be ruled out. Pressure compaction enhances the closeness between composite particles leading to the formation of conducting channels, thus providing adequate electrical conduction. The porous structure and increasing electrically conducting nature of ABS-charcoal composites with the increasing carbonization temperature observed in FESEM micrographs (Fig. 4) corroborate the increase in total SE with enhanced carbonization temperature-treated charcoals in ABS composites.

Earlier, the SE performance of composites in the same ABS matrix with nano-fibril MWCNTs and laminar graphite was studied. ${ }^{42}$ The maximum value of total $\mathrm{SE} \sim 40 \mathrm{~dB}$ with small quantity $(5 \mathrm{wt} \%)$ of MWCNTs in ABS achieved was 

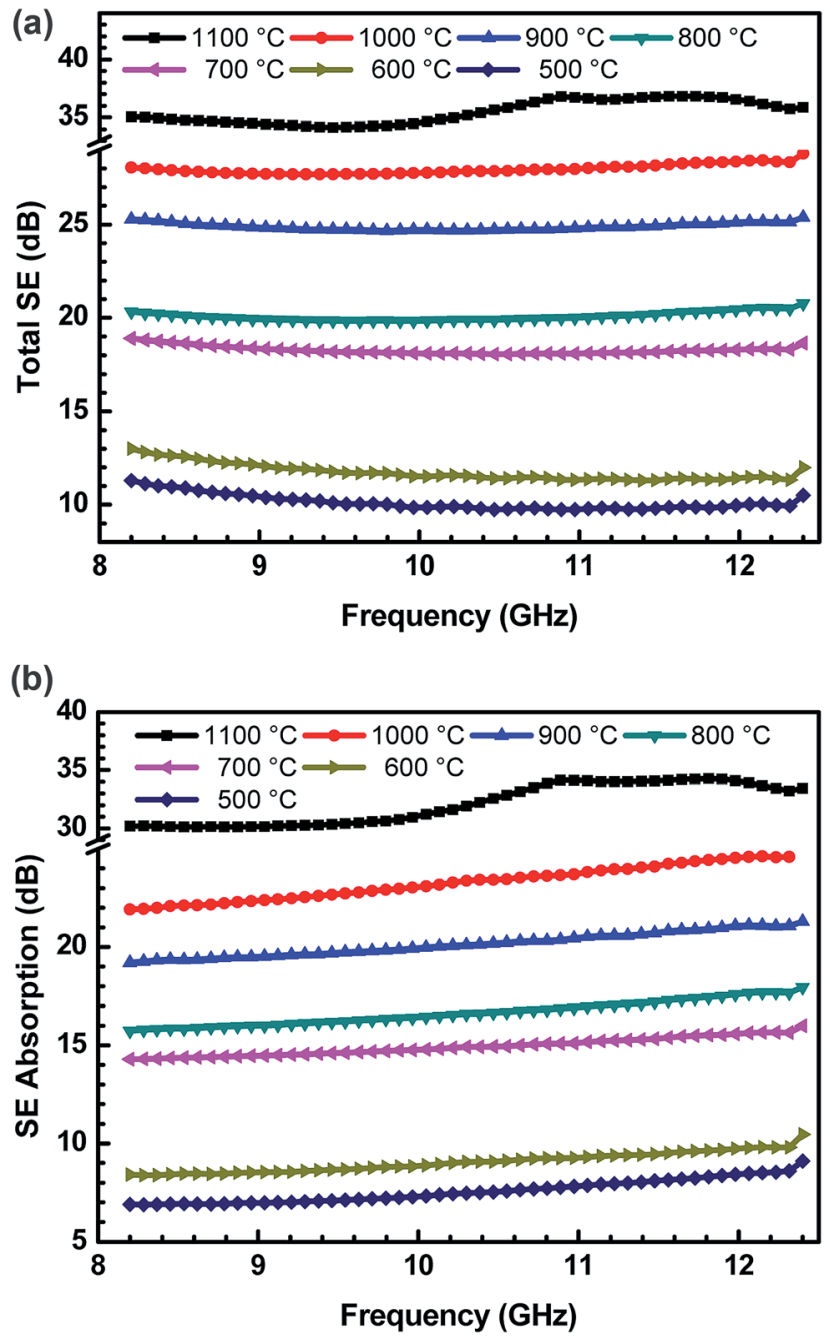

Fig. 8 (a): Variation in total SE for ABS-charcoal composites as a function of frequency having charcoals treated at different temperatures (from $500^{\circ} \mathrm{C}$ to $1100^{\circ} \mathrm{C}$ ). (b): Variation of SE absorption for ABS-charcoal composites as a function of frequency containing charcoals treated at different temperatures.

comparatively higher because of MWCNTs' high aspect ratio and good conductivity, but high cost and difficulty in the processing of MWCNTs in a polymer matrix hamper its commercial applications.

Reflection and absorption are correspondingly the surface and volume phenomena for primary EMI shielding mechanism. Both are known to increase with the increase in the conductivity of polymer composites. As reflection $(R)$ occurs before absorption $(A)$, the intensity of the EM wave that enters inside the shield after primary reflection is based on the quantity $(1-R)$. Therefore, in order to get a true picture, the absorption $(A)$ can be normalized using the factor $(1-R)$ to yield effective absorbance $\left(A_{\text {eff }}\right)$ using the following relation, ${ }^{53,54}$

$$
A_{\text {eff }}=\frac{(1-R-T)}{(1-R)}
$$

Fig. 9 shows the variation in $A_{\text {eff }}$ of ABS charcoal composites at a frequency of $8.2 \mathrm{GHz}$ for different carbonization temperatures. From the previous knowledge, ${ }^{42}$ the $A_{\text {eff }}$ values have been extracted from $S_{11} / S_{12}$ parameters. The expression for $\mathrm{SE}_{\mathrm{Abs}}$ can be written as, ${ }^{55}$

$$
\mathrm{SE}_{\mathrm{Abs}}=8.68 t \sqrt{\sigma \mu f}
$$

$t, \sigma, \mu$ and $f$ are the thickness of the shield, electrical conductivity, permeability and frequency of the EM radiation, respectively. Since charcoal is not a magnetic material, the value of $\mu$ is $\sim 1$ and for a fixed frequency and thickness, absorption primarily depends on the conductivity of the shielding material. $A_{\text {eff }}$ increases rapidly with the carbonization temperature up to $700{ }^{\circ} \mathrm{C}$ through $600{ }^{\circ} \mathrm{C}$ and become saturated for higher carbonization temperature $\left(>700^{\circ} \mathrm{C}\right)$ charcoals in ABS, similar to the conductivity behaviour in Fig. 3. Initially up to $600^{\circ} \mathrm{C}$, the abrupt absorption is little sluggish compared to the conductivity performance. In all probabilities, the reason behind this lies with the absorption and conductivity mechanisms.

Fig. 10 demonstrates the behaviour of total SE, SE absorption and SE reflection of ABS-charcoal composites as a function of carbonization temperature of the charcoal at a certain representational frequency of $11.6 \mathrm{GHz}$.

It may be seen that total $\mathrm{SE}$ and evaluated value of $\mathrm{SE}$ absorption increase, whereas SE reflection, which has a comparatively smaller value, remains unaffected with the rise in the carbonization temperature of charcoals. Thus, the major contribution in total SE is from SE absorption. For a nonmagnetic material, shielding due to absorption is mainly due to ohmic loss. ${ }^{56}$ The increase in SE absorption is attributed to the increase in the $\sigma$ value of composites with equal quantities of charcoals treated at increasing temperatures. In FESEM images, the foam-like structures has been observed that offer lots of interfaces. The incident EM radiation reflected and scattered by these interfaces is highly absorbed before escaping from the sample. ${ }^{57}$ The FTIR study reveals the presence of a number of functional groups within the carbonized charcoal,

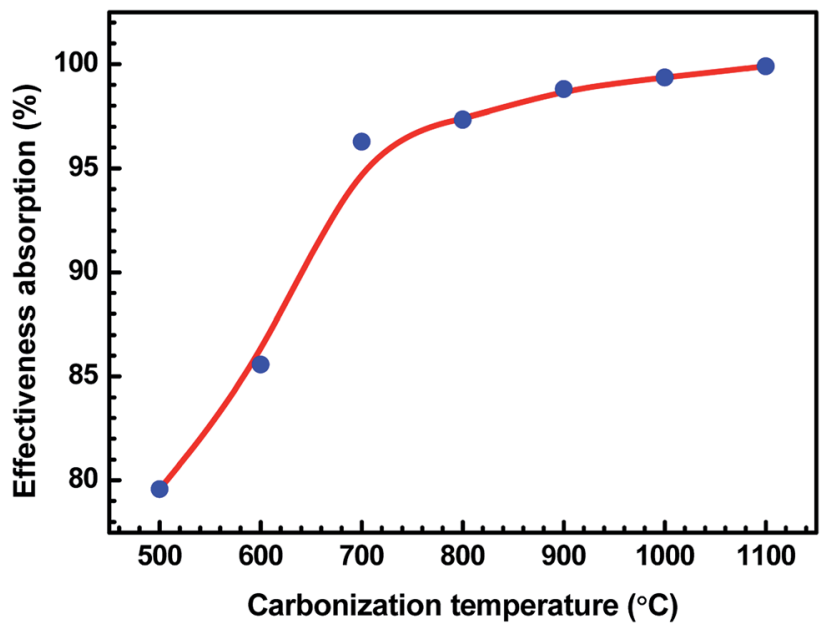

Fig. 9 Variation in $A_{\text {eff }}$ of $A B S$ charcoal composites at a frequency of 8.2 $\mathrm{GHz}$ for different carbonization temperatures. 


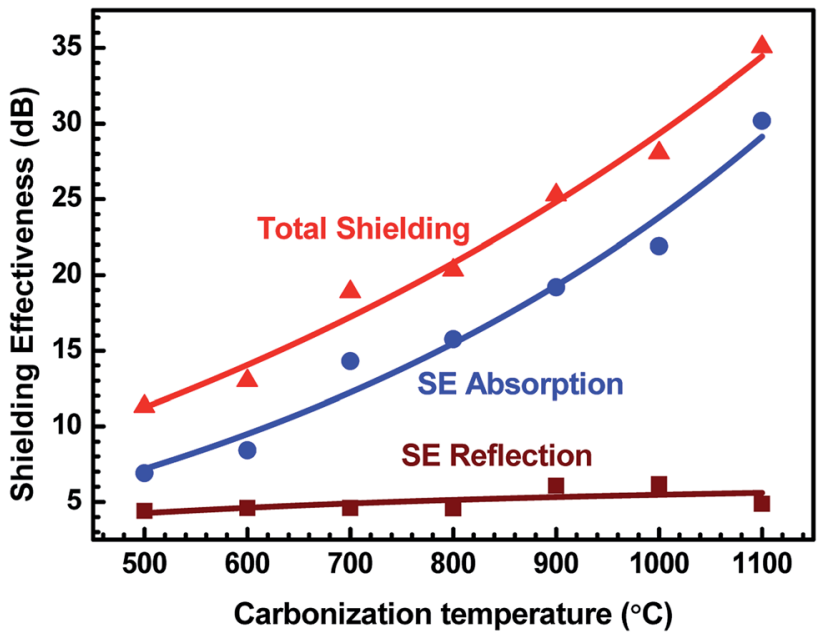

Fig. 10 Variation of total SE, SE absorption and SE reflection of ABS/ charcoal composites as a function of carbonization temperature of charcoals at a certain frequency of $11.6 \mathrm{GHz}$.

and in the conductivity section, the possibility of the presence of defects has been discussed. These functional groups and defects create asymmetric distribution of charges, resulting in the development of dipoles within the composites. ${ }^{58}$ If an external EM field has been applied, dipoles will rotate and convert the EM energy into heat due to relaxation loss. ${ }^{58,59}$ The rise of carbonization temperature reduces the internal friction resulting in an increase in loss tangent. ${ }^{60}$

It is observed that $\varepsilon^{\prime}$ remains almost constant to a moderate value of $\sim 15$ for all the composites, whereas $\sigma$ increases to a maximum value of $4.81 \mathrm{~S} \mathrm{~cm}^{-1}$ for the ABS-charcoal composite having charcoals treated at $1100{ }^{\circ} \mathrm{C}$. Hence, the increase in $\sigma$ is supposed to be responsible for good absorption. A constant value of SE reflection obtained may be related to the amount of charcoal present in the composite, which is fixed for all the composites. The total SE is absorption dominant in all the samples. The highest total $\mathrm{SE}$ of $36.8 \mathrm{~dB}$ at $11.6 \mathrm{GHz}$ (1100 ${ }^{\circ} \mathrm{C}$ carbonization temperature) has the major contribution of SE absorption $(\sim 34.2 \mathrm{~dB})$. The charcoal located at interfacial positions surrounded by ABS is assumed to be responsible for the observed dielectric properties due to space charge polarization at the interfaces. The moderate dielectric constant and good conductivity improve the absorption at the interface. Sufficient dissipation of energy probably occurs as a result of the inflow of EM waves through composites of larger chunks seen in FESEM micrographs (Fig. 4(c and d)).

The investigation of EMI shielding mechanism of ABS composites filled with different temperature-treated equalquantity charcoals in terms of power coefficients would be thought-provoking.

Table 1 displays $T, R$, and $A$ of these composites as a function of the carbonization temperature of filler charcoals. As the carbonization temperature increases, $T$ largely decreases, indicative of the enhanced EMI shielding ability. $R$ reveals an increase with the carbonization temperature, which should be ascribed to the impedance mismatch ${ }^{59}$ at interfaces induced by the increased conductivity of charcoals. In the present research, increased conductivities are brought by carbonization temperatures since the quantity of the charcoal (20 wt\%) is the same. Absorption $A$ undergoes a continuous decrease ascribed to the increase in $R$, as the carbonization temperature realised increased the conductivity. However, $R$ does not increase significantly from $900{ }^{\circ} \mathrm{C}$ onwards since the conductivity almost becomes saturated above this temperature. Increase in $A$ on decreasing carbonization temperature represents the improvement of electrical dipoles.

\section{Conclusion}

SE is found to be increasing for ABS-charcoal composites containing equal quantities of carbonized charcoal (20 wt $\%$ ) treated with stepwise increasing temperatures. The increase in $\sigma$ with the carbonization temperature is attributed to the improvement in the EMI shielding behaviour of ABS-charcoal composites. EDAX executed on these temperature-treated charcoals corroborates the increase in the carbon content and thus the $\sigma$ performance. The ABS-charcoal composite having the $1100{ }^{\circ} \mathrm{C}$ temperature-treated charcoal showed the maximum absorption-dominated total SE of $\sim 36.8 \mathrm{~dB}$ at $11.6 \mathrm{GHz}$. It is significant to see how the same charcoal taken in equal amounts but treated at different temperatures behaves in the ABS matrix. SE reflection of composites does not change with the carbonization temperature of filler charcoals although $\sigma$ of composites increases. A sudden change in the $A_{\text {eff }}$ of the composites with an increasing carbonization temperature is almost in tune with the $\sigma$ behaviour. The findings reasonably indicate the decisive importance of ABS composites containing different temperature-treated equal-quantity charcoals for tailor-made product application.

\section{Conflicts of interest}

There is no conflicts to declare.

\section{Acknowledgements}

The authors are grateful to the Department of Science and Technology, Government of India for logistic support of this work.

\section{References}

1 N. Joseph, S. K. Singh, R. K. Sirugudu, V. R. K. Murthy, S. Ananthakumar and M. T. Sebastian, Mater. Res. Bull., 2013, 48, 1681-1687.

2 S. H. Lee, S. Yu, F. Shahzad, J. P. Hong, W. N. Kim, C. Park, S. M. Hong and C. M. Koo, Compos. Sci. Technol., 2017, 144, 57-62.

3 S. Geetha, K. Satheesh Kumar, C. R. Rao, M. Vijayan and D. Trivedi, J. Appl. Polym. Sci., 2009, 112, 2073-2086.

4 J. Cao and D. Chung, Cem. Concr. Res., 2003, 33, 1737-1740. 5 Y. Wu, Z. Wang, X. Liu, X. Shen, Q. Zheng, Q. Xue and J.-K. Kim, ACS Appl. Mater. Interfaces, 2017, 9, 9059-9069. 
6 M. Cvek, R. Moucka, M. Sedlacik, V. Babayan and V. Pavlínek, Smart Mater. Struct., 2017, 26, 095005.

7 A. G. Koniuszewska and J. W. Kaczmar, Prog. Rubber, Plast. Recycl. Technol., 2016, 32, 1-24.

8 J. Joo and A. Epstein, Appl. Phys. Lett., 1994, 65, 2278-2280.

9 R. Kumaran, M. Alagar, S. Dinesh Kumar, V. Subramanian and K. Dinakaran, Appl. Phys. Lett., 2015, 107, 113107.

10 H.-C. Lee, J.-Y. Kim, C.-H. Noh, K. Y. Song and S.-H. Cho, Appl. Surf. Sci., 2006, 252, 2665-2672.

$11 \mathrm{~J} . \mathrm{Wu}$ and D. Chung, Carbon, 2003, 41, 1313-1315.

12 H. Kim, K. Kim, C. Lee, J. Joo, S. Cho, H. Yoon, D. Pejaković, J.-W. Yoo and A. Epstein, Appl. Phys. Lett., 2004, 84, 589-591.

13 Z. Min, H. Yang, F. Chen and T. Kuang, Mater. Lett., 2018, 230, 157-160.

14 Q. Zhang, A. Prabhu, A. San, J. F. Al-Sharab and K. Levon, Biosens. Bioelectron., 2015, 72, 100-106.

15 Y. Zhou, Q. Zhang, J. Wu, C. Xi and M. E. Meyerhoff, J. Mater. Chem. B, 2018, 6, 6142-6152.

16 Q. Zhang, H. S. Majumdar, M. Kaisti, A. Prabhu, A. Ivaska, R. Österbacka, A. Rahman and K. Levon, IEEE Trans. Electron Devices, 2015, 62, 1291-1298.

17 J.-M. Thomassin, X. Lou, C. Pagnoulle, A. Saib, L. Bednarz, I. Huynen, R. Jerôme and C. Detrembleur, J. Phys. Chem. C, 2007, 111, 11186-11192.

18 M. S. Cao, J. C. Shu, X. X. Wang, X. Wang, M. Zhang, H. J. Yang, X. Y. Fang and J. Yuan, Ann. Phys., 2019, 1800390.

19 B. Wen, M. Cao, M. Lu, W. Cao, H. Shi, J. Liu, X. Wang, H. Jin, X. Fang and W. Wang, Adv. Mater., 2014, 26, 34843489.

20 M.-S. Cao, W.-L. Song, Z.-L. Hou, B. Wen and J. Yuan, Carbon, 2010, 48, 788-796.

21 S.-Y. Wang and C.-P. Hung, J. Wood Sci., 2003, 49, 450-454.

22 K. Ishimaru, T. Hata, P. Bronsveld, T. Nishizawa and Y. Imamura, J. Wood Sci., 2007, 53, 442-448.

23 K. Nishimiya, T. Hata, Y. Imamura and S. Ishihara, J. Wood Sci., 1998, 44, 56-61.

24 K. Nishimiya, T. Hata, H. Kikuchi and Y. Imamura, J. Wood Sci., 2004, 50, 177-181.

25 S. Li and D. Li, Mater. Lett., 2014, 137, 409-412.

26 L. W. Mckeen, Fatigue and tribological properties of plastics and elastomers, A. AC02498715, Plastics Design Library, 1997.

27 M. Kutz, Applied plastics engineering handbook: processing and materials, William Andrew, 2011.

28 T. Okabe, K. Saito, M. Fushitani and M. Otsuka, J. Porous Mater., 1996, 2, 223-228.

29 N. Phonphuak and S. Thiansem, ScienceAsia, 2011, 37, 120124.

30 S. Sharma, V. Gupta, R. Tandon and V. Sachdev, RSC Adv., 2016, 6, 18257-18265.

31 B. Janković, V. Dodevski, M. Stojmenović, S. Krstić and J. Popović, J. Therm. Anal. Calorim., 2018, 1-16.

32 M. Arora, M. Wahab and P. Saini, J. Polym., 2014, 2014, 193058.

33 F. Davrieux, P. L. A. Rousset, T. C. M. Pastore, L. A. d. Macedo and W. F. Quirino, Quim. Nova, 2010, 33, 1093-1097.
34 N. Labbé, D. Harper, T. Rials and T. Elder, J. Agric. Food Chem., 2006, 54, 3492-3497.

35 S. Yao, K. Zhang, K. Jiao and W. Hu, Energy Explor. Exploit., 2011, 29, 1-19.

36 T. Schädle, B. Pejcic and B. Mizaikoff, Anal. Methods, 2016, 8, 756-762.

37 M. Somerville and S. Jahanshahi, Renewable energy, 2015, 80, 471-478.

38 M. Kumar and R. Gupta, J. Mater. Sci., 1993, 28, 440-444.

39 K. Ouchi, Fuel, 1967, 46, 71-84.

40 W.-L. Song, M.-S. Cao, Z.-L. Hou, X.-Y. Fang, X.-L. Shi and J. Yuan, Appl. Phys. Lett., 2009, 94, 233110.

41 B. Wen, M.-S. Cao, Z.-L. Hou, W.-L. Song, L. Zhang, M.-M. Lu, H.-B. Jin, X.-Y. Fang, W.-Z. Wang and J. Yuan, Carbon, 2013, 65, 124-139.

42 V. Sachdev, S. Sharma, M. Tomar, V. Gupta and R. Tandon, RSC Adv., 2016, 6, 45049-45058.

43 J. Diaz-Teran, D. Nevskaia, A. López-Peinado and A. Jerez, Colloids Surf., A, 2001, 187, 167-175.

44 M. E. Leyva, G. M. Barra, A. C. Moreira, B. G. Soares and D. Khastgir, J. Polym. Sci., Part B: Polym. Phys., 2003, 41, 2983-2997.

45 T. T. Fang, H. L. Hsieh and F. S. Shiau, J. Am. Ceram. Soc., 1993, 76, 1205-1211.

46 M. H. Al-Saleh, W. H. Saadeh and U. Sundararaj, Carbon, 2013, 60, 146-156.

47 I. Otero-Navas, M. Arjmand and U. Sundararaj, Polymer, 2017, 114, 122-134.

48 C. C. $\mathrm{Ku}$ and R. Liepins, Electrical properties of polymers, Hanser Publishers, New York, 1987.

49 J. Yacubowicz, M. Narkis and L. Benguigui, Polym. Eng. Sci., 1990, 30, 459-468.

50 S. Ramo, J. R. Whinnery and T. Van Duzer, Fields and waves in communication electronics, John Wiley \& Sons, 2008.

$51 \mathrm{M}$. T. Sebastian, Dielectric materials for wireless communication, Elsevier, 2010.

52 V. Choudary, S. Dhawan and P. Saini, EMI Shielding Theory and Development of New Materials, Research Signpost: Kerala, India, 2012, pp. 67-100.

53 H.-R. Kim, B.-S. Kim and I.-S. Kim, Mater. Chem. Phys., 2012, 135, 1024-1029.

54 W.-L. Song, M.-S. Cao, M.-M. Lu, S. Bi, C.-Y. Wang, J. Liu, J. Yuan and L.-Z. Fan, Carbon, 2014, 66, 67-76.

55 S. Ganguly, P. Bhawal, R. Ravindren and N. C. Das, J. Nanosci. Nanotechnol., 2018, 18, 7641-7669.

56 F. Sharif, M. Arjmand, A. A. Moud, U. Sundararaj and E. P. Roberts, ACS Appl. Mater. Interfaces, 2017, 9, 1417114179.

57 H.-Y. Wu, L.-C. Jia, D.-X. Yan, J.-f. Gao, X.-P. Zhang, P.-G. Ren and Z.-M. Li, Compos. Sci. Technol., 2018, 156, 87-94.

58 M. Cao, X. Wang, W. Cao, X. Fang, B. Wen and J. Yuan, Small, 2018, 14, 1800987.

59 M. S. Cao, X. X. Wang, M. Zhang, J. C. Shu, W. Q. Cao, H. J. Yang, X. Y. Fang and J. Yuan, Advanced Functional Materials, 2019, p. 1807398.

60 W.-Q. Cao, X.-X. Wang, J. Yuan, W.-Z. Wang and M.-S. Cao, J. Mater. Chem. C, 2015, 3, 10017-10022. 